\title{
Keanekaragaman Kepiting Biola (Uca) di Kawasan Hutan Mangrove Kuala Langsa Provinsi Aceh
}

Violin Crap Diversity (Uca) In Mangrove Forests Of Kula Langsa, Aceh Province

\author{
Ruwaida $^{1}$, Marjanah ${ }^{2}$, Abdul L. Mawardi ${ }^{3}$ \\ Prodi Pendidikan Biologi Fakultas Keguruan Dan Ilmu Pendidikan \\ Universitas Samudra \\ Email : ruwaidaidaa97@gmail.com
}

\begin{abstract}
ABSTRAK
Hutan mangrove merupakan tipe ekosistem yang terdapat pada ekosistem mangrove yang selalu digenangi air laut dan dipengaruhi oleh pasang surut air laut, dengan kondisi berlumpur, berpasir atau lumpur berpasir. Kepiting biola (Uca) merupakan salah satu jenis satwa yang hidup dalam lubang atau berendam dalam substrat pada ekosistem mangrove. Penelitian ini bertujuan untuk mengetahui keanekaragaman kepiting biola (Uca) dan untuk mengetahui spesies kepiting biola (Uca) manakah yang paling dominan dijumpai di Kawasan Hutan Mangrove Kuala Langsa, Provinsi Aceh. Metode yang digunakan dalam penelitian ini adalah metode survei dengan penentuan lokasi pengambilan sampel secara purposive sampling. Hasil penelitian menyatakan bahwa keanekaragaman kepiting biola (Uca) tergolong dalam katagori sedang dengan nilai $\mathrm{H}^{\prime}$ yaitu 1,434. Dan spesies yang paling dominan dijumpai adalah Uca tetragonon.
\end{abstract}

Kata Kunci: Keanekaragaman, Kepiting Biola, Mangrove

\begin{abstract}
Mangrove forest is a type of ecosystem found in mangrove ecosystems that are always inundated by sea water and influenced by the tides of sea water, with conditions of muddy, sandy or sandy mud. Violin crab (Uca) is a type of animal that lives in holes or soaks in the substrate in the mangrove ecosystem. This study aims to determine the diversity of violin crab (Uca) and to determine which species of violin crab (Uca) are most dominant in the Mangrove Forest Area of Kuala Langsa, Aceh Province. The method used in this study is a survey method with the determination of the sampling location by purposive sampling. The results showed that the diversity of violin crab (Uca) belonged to the medium category with an $H$ 'value of 1.434. And the most dominant species found is Uca tetragonon.
\end{abstract}

Keywords: Diversity, Biola Crab, Mangrove

\section{PENDAHULUAN}

Indonesia merupakan Negara kepulauan yang terdiri dari 13.667 pulau dan wilayah pantai sepanjang 54.716 kilometer. Wilayah pantai (pesisir) banyak banyak ditumbuhi hutan mangrove 
(Karimah, 2017:52). Hutan mangrove merupakan suatu ekosistem yang terdapat didaerah pantai yang secara teratur digenangi air laut dan dipengaruhi oleh pasang surut air laut, dengan kondisi tanah berlumpur dan berpasir (Hasan, 2014: 676).

Mangrove merupakan tempat tempat penimbunan bahan organik dan pelumpuran (Karuniastuti, 2013: 2). Hutan mangrove sangat penting bagi kehidupan kepiting biola sebagai tempat siklus hidup hidupnya tetap terjaga dengan baik. (Siburian, dkk., 2014: 2). Kepiting biola adalah fauna yang hidup pada ekosistem mangrove yang berfungsi sebagai keystone species. (Hamidah et al., 2014: 922).

Genus Uca ini adalah hewan unik yang memiliki tubuh yang kecil dan warna yang bervariasi. Jenis uca ini berasal dari Ordo Decapoda dan famili Ocypodidae. (Murniati dan Pratiwi, 2015:922). Genus Uca ini hanya mampu bertahan hidup di beberapa wilayahgenus uca ini hanya 19 jenis yang sudah teridentifikasi di Indonesia dari 97 jenis dari jumlah yang ada di Indonesia (Rosenberg, 2001: 147162).

Aceh merupakan provinsi yang banyak ditumbuhi mangrove terutama daerah pantai timur meliputi pesisir Aceh Timur, Aceh Tamiang serta pesisir Kota Langsa yang luasnya mencapai 63.832,99
Ha. Hutan mangrove yang sudah Diidentifikasi di Provinsi Aceh yaitu 301 jenis dengan rata-rata kerapatan pohon mancapai 1.811 Ha (Bapedal, 2014).

Tujuan dari penelitian ini untuk mengetahui Keanekaragaman Kepiting Biola (Uca) di Kawasan Hutan Mangrove Kuala Langsa Provinsi Aceh dan mengetahui spesies Kepiting Biola manakah yang paling dominan di Kawasan Hutan Mangrove Kuala Langsa Provinsi Aceh. Oleh karena itu penelitian tentang keanekaragaman Kepiting Biola di Kawasan Hutan Mangrove Kuala Langsa Provinsi Aceh mermberikan informasi kepada masyarakat yang ada di Kuala Langsa tentang keanekaragaman kepiting biola (Uca), bahwa ada ekosistem unik dan menguntungkan untuk pertumbuhan mengrove yang ada disekitar masyarakat.

\section{METODOLOGI PENELITIAN}

Penelitian ini dilaksanakan dari bulan Oktober sampai November 2020 di Kawasan Hutan Mangrove Kuala Langsa, Provinsi Aceh. Alat dan bahan yang digunakan dalam penelitian ini adalah: alat tulis, kamera hp, tali rafia, meteran, soil tester, salinometer, kertas lebel, toples kecil dan teropong, Alkohol 70\% dan Kepiting Biola.

Penelitian ini merupakan penelitian deskriptif kuantitatif. Metode yang 
digunakan pada penelitian ini adalah dengan pendekatan metode survei dan observasi langsung dilapangan (Suprayogi et al., 2014). Berdasarkan hasil observasi yang telah dilakukan lokasi pengambilan sampel dibagi menjadi 2 stasiun. Berikut ini lokasi pengambilan sampel pada II stasiun yaitu:

1. Stasiun I $\left(4^{\circ} 31^{\prime} 23,7^{\prime \prime} \mathrm{N}\right.$ dan 98 00’30,0’'E) berada didekat pelabuhan kuala langsa, stasiun ini memiliki substrat pasir berbatu.

2. Stasiun II $\left(4^{\circ} 31^{\prime} 49,77^{\prime} N\right)$ dan (9801'27, 4'E) berada di dekat lapangan terbang kuala langsa, stasiun ini memliki substrat lumpur dan ditumbuhi mangrove kecil.

Penelitian dilakukan berdasarkan metode purposive sampling. Penentuan garis transek disesuaikan dengan kondisi lapangan.

Langkah - langkah pengambilan sampel adalah sebagai berikut:

1. Dari hasil observasi lapangan waktu yang cocok untuk penelitian genus Uca adalah pukul 09:00- 12:00 WIB kondisi air laut surut.

2. Setiap stasiun penelitian memiliki 1 transek yaitu 100 meter yang terdiri 33 plot dengan ukuran masingmasing plot $1 \mathrm{x} 1 \mathrm{~m}$
3. Sampe diambil kurang lebih 5 menit setelah kepiting biola berada didalam plot, kepiting biola (Uca) yang berada pada permukaan tanah diamati dengan menggunakan teropong, sedangkan kepiting biola (Uca) yang berada didalam liangnya pada saat pengambilan sampel maka dilakukan dengan cara metode digging yaitu penggalian lubang kepiting biola (Uca) sedalam $30 \mathrm{~cm}$ untuk mendapatkan sampel kepiting biola (Uca) dengan menggunakan alat sekop kecil.

4. Sampel yang telah diambil dimasukkan kedalam toples yang telah dikasih lebel yang berisi alkohol $70 \%$ lalu tutup toples hingga rapat.

5. Pengambilan Uca berdasarkan jumlah spesies dan individu, lalu dicatat jumlah spesies dan individu yang terdapat didalam masingmasing plot.

6. Setiap jenis kepiting biola (Uca) diawetkan dengan alkohol $70 \%$ sebagai sampel.

\section{Analisis Data}

Semua data yang telah terkumpul kemudian dianalisis dengan mengguna kan rumus indeks keanekaragaman yaitu: Indek Keanekaragaman (Shanon-Wiener) mempunyai beberapa katagori menurut 
(Odum, 1993: 52) yang meliputi 3 kriteria berdasarkan kondisi organisme sebagai berikut:

$\mathrm{H}^{\prime}<1$ : Keanekaragaman sangat rendah.

$>1<\mathrm{H}^{\prime}<3$ : Keanekaragaman sedang.

$>\mathrm{H}^{\prime}>3:$ Keanekaragaman tinggi.
Berdasarkan penelitian yang telah dilakukan Keanekaragaman Kepiting Biola (Uca) di Hutan Mangrove Kuala Langsa, Provinsi Aceh ditemukan sebanyak 6 spesies Kepiting Biola (Uca). Untuk melihat Keanekaragaman Kepiting Biola dapat dilihat pada Tabel 1.

\section{HASIL DAN PEMBAHASAN}

1. Indeks Keanekaragaman (H')

Tabel. 1 Keanekaragaman $U c a$ di lokasi penelitian (Diversity of Uca at the research location).

\begin{tabular}{|c|c|c|c|c|c|c|}
\hline Famili & Genus & Spesies & Jumlah & $\mathbf{P i}$ & $\ln \mathbf{P i}$ & $\mathbf{P i} \ln \mathbf{P i}$ \\
\hline Ocypodidae & Uca & Uca tetragonon & 56 & 0,348 & $-1,056$ & $-0,367$ \\
\hline Ocypodidae & $U c a$ & Uca vocans & 27 & 0,168 & $-1,786$ & $-0,299$ \\
\hline Ocypodidae & Uca & Uca annulipes & 36 & 0,224 & $-1,498$ & $-0,335$ \\
\hline Ocypodidae & Uca & Uca vomeris & 5 & 0,031 & $-3,472$ & $-0,108$ \\
\hline Ocypodidae & $U c a$ & Uca perplexa & 35 & 0,217 & $-1,526$ & $-0,332$ \\
\hline Ocypodidae & Uca & Uca dussumeiri & 2 & 0,012 & $-4,388$ & $-0,055$ \\
\hline \multicolumn{2}{|c|}{ Total Individu Seluruh Spesies } & 6 & 161 & 1,000 & & $-1,496$ \\
\hline
\end{tabular}

Dari tabel 1 Keanekaragaman

Kepiting Biola di Kawasan Hutan Mangrove Kuala Langsa Provinsi Aceh dengan nilai $\mathrm{H}^{\prime}=1,496$ dengan katagori sedang. Keanakeragaman Kepiting Biola (Uca) berdasarkan stasiun dapat dilihat pada grafik 1 . 


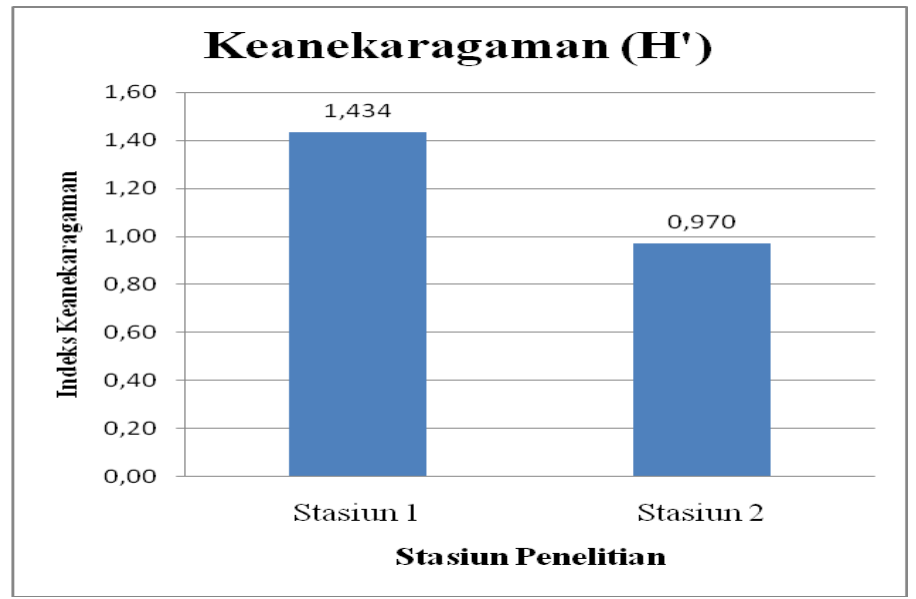

Grafik 1. Keanekaragaman Kepiting Biola (Uca) Berdasarkan Stasiun Penelitian (Violin Crab Diversity (Uca) Based on Research Stations).

Berdasarkan grafik 1 dapat dilihat dari kedua stasiun memiliki nilai keanekaragaman yang berbeda. Stasiun 1 nilai $H^{\prime}=1,434$ degan katagori sedang sedangkan pada stasiun 2 nilai $\mathrm{H}^{\prime}=0,970$ dengan katagori rendah.

\section{Faktor Lingkungan Perairan}

Hasil pengukuran kondisi Lingkungan di lokasi penelitian ditemukan kondisi lingkungan yang bervariasi. Kondisi fisika- kimia yang meliputi suhu, $\mathrm{pH}$ dan salinitas dilokasi peenelitian yang telah dilakukan dapat dilihat pada tabel 2 .

Tabel. 2 Nilai Faktor Fisika-Kimia di Lokasi Penelitian (Value of Physical-Chemical Factors at Research Sites.).

\begin{tabular}{|l|l|c|c|c|}
\hline No. & \multicolumn{1}{|c|}{ Lokasi } & Suhu & pH & Salinitas \\
\hline 1. & Stasiun 1 & $26^{\circ} \mathrm{C}$ & 5,5 & $20 \% 00$ \\
\hline 2. & Stasiun 2 & $32^{\circ} \mathrm{C}$ & 5,2 & $20 \% 00$ \\
\hline
\end{tabular}

Berdasarkan Tabel 2 diketahui suhu pada stasiun I berkisar antara $26^{\circ} \mathrm{C}$ dan pada stasiun 2 berkisar antara $32^{\circ} \mathrm{C}$. Nilai derajat keasaman $(\mathrm{pH})$ pada stasiun 1 berkisar antara 5,5 dan pada stasiun 2 berkisar antara 5,2 dan nilai untuk salinitas dari 2 stasiun nilai nya sama yaitu $20 \%$.

\section{PEMBAHASAN}

Berdasarkan hasil penelitian dikawasan Hutan Mangrove Kuala Langsa Provinsi Aceh Keanekaragaman Kepiting Biola $(U c a)$ secara umum memiliki indeks keanekaragaman $H^{\prime}=1,496$ dengan katagori sedang. Hal ini dikarenakan kondisi lingkungan yang sudah mulai terganggu dengan berbagai macam 
aktifitas masyarakat yaitu akibat tempat wisata, nelayan, pelebaran jalan, pertambakan penduduk, pembuangan limbah rumah tanggga dan berbagai aktifitas lainnya. Keanekaragaman kepting biola $(U c a)$ sangat berpengaruh terhadap takanan yang diterima oleh kepiting biola (Uca) dan akan mengalami stress (Putriningtias, A. et al., 2019: 104).

Hasil penelitian ditemukan 6 spesies kepiting biola (Uca) dengan spesies yang paling dominan adalah $U c a$ tetragonon. Hal ini disebabkan karena kondisi lingkungan yang sudah mulai terganggu oleh berbagai macam aktifitas masyarakat sehingga Uca tetragonon tidak dapat bertahan hidup pada lingkungan yang sudah terganggu. Uca tetragonon ini akan masuk ke liangnya pada saat air laut pasang. Tingginya frekuensi pada habitat yang terendam air sangat berpengaruh terhadap kepadatan Uca tetragonon (Yulianto, 2006). Sedangkan yang paling rendah adalah Uca dussumeiri. Hal ini disebabkan karena beberapa faktor lingkungan dan kondisi substrat yang sudah tercemar dan pelebaran lahan mangrove untuk berbagai macam aktifitas masyarakat. Pratiwi (2012: 240) menyatakan bahwa Uca dussumeiri dapat beradaptasi dengan baik jika faktor lingkungannya luas pada eksistem mangrove.
Jika dilihat berdasarkan stasiun Keanekaragaman Kepiting Biola (Uca) memiliki indeks keanekaragaman yang berbeda yaitu pada stasiun $1 \mathrm{H}^{\prime}=1,343$ berada dalam katagori sedang dan pada stasiun $2 \mathrm{H}^{\prime}=0,970$ berada dalam katagori rendah. Rendahnya suatu keanekaragaman pada stasiun 2 disebabkan dengan pelebaran lahan untuk pembuatan bandara dan lokasinya pada substrat lumpur lunak yang tidak ditumbuhi pohon besar sehingga tidak aman untuk penahan liang kepiting biola $(U c a)$, liangnya akan rusak pada saat air laut pasang. Menurut Murniati dan Pratiwi (2015) populasi kepiting biola (Uca) cenderung lebih besar pada substrat yang padat dibandingkan substrat yang lunak. Substrat yang padat memberikan konstruksi yang lebih kuat sehingga lebih aman untuk penahan liangnya. Jika ekosistem mangrove dalam keadaan tertekan atau terdegradasi maka keanekaragamannya rendah (Putriningtias, A. et al., 2019: 105).

Berdasarkan hasil pengukuran $\mathrm{pH}$ dari dua stasiun didapatkan nilai $\mathrm{pH}$ pada stasiun 1 dengan kisaran 5,2 dan pada stasiun 2 dengan kisaran 5,5, nilai $\mathrm{pH}$ nya sesuai dengan habitat Kepting Biola (Uca). $\mathrm{pH}$ normal untuk Kepiting Biola (Uca) adalah 5,0-9,0 (Pratiwi \& Astuti 2012: 56). Pada setiap stasiun penelitian masih memiliki kisaran $\mathrm{pH}$ yang ideal bagi 
kehidupan biota perairan, sehingga serasah yang dihasilkan oleh Kepiting Biola dapat mencukupi kehidupannya karena memiliki $\mathrm{pH}$ yang baik. $\mathrm{pH}$ yang $<5$ dan $>9$ akan menciptakan kondisi yang tidak menguntungkan bagi kehidupan makrozoobenthos termasuk Kepiting Biola (Uca) Pratiwi (2010: 927). Nilai pH pada lokasi penelitian berada pada kisaran $5<\mathrm{pH}<9$ maka dapat dikatakan bahwa $\mathrm{pH}$ pada setiap stasiun sesuai untuk habitat Kepiting Biola (Uca) (Rizal., et al, 2017: 37)

Suhu untuk lokasi penelitian di Kawasan Hutan Mangrove Kuala Langsa Provinsi Aceh pada stasiun 1 dengan kisaran $26^{\circ} \mathrm{C}$ dan pada stasiun 2 dengan kisaran $32^{\circ} \mathrm{C}$, karena penelitian ini dilakukan dipagi hari yaitu pukul (09.0012.00 WIB). Hasil pengukuran suhu tersebut masih dalam katagori baik untuk tempat hidup Kepiting Biola (Uca). Menurut Cholik (2005: 21), suhu yang sesuai untuk Kepiting Biola (Uca) adalah $18^{\circ} \mathrm{C}-35^{\circ} \mathrm{C}$, sedangkan suhu ideal adalah $25^{\circ} \mathrm{C}-30^{\circ} \mathrm{C}$.

Berdasarkan hasil pengukuran salinitas pada kedua stasiun adalah $20 \%$ dan masih sesuai untuk kehidupan kapiting biola. Salinitas optimum untuk Crustacea bekisar 23 - $26 \%$ (Permata., et al, 2018: 927).

\section{KESIMPULAN}

Berdasarkan hasil penelitian yang telah dilakukan dan hasil analisis data, maka dapat disimpulkan sebagai berikut :

1. Keanekaragaman kepiting biola di lokasi penelitian masih berada dalam katagori sedang dengan nilai indeks keanekaragaman yaitu $H^{\prime}=1,434$.

2. Kepiting biola (Uca) yang paling dominan di jumpai di Kawasan Hutan Mangrove Kuala Langsa, Provinsi Aceh yaitu Uca tetragonon.

\section{DAFTAR PUSTAKA}

BAPEDAL, 2014. Laporan Status Lingkungan Hidup Daerah Provinsi Aceh. ACEH, BAPEDAL.

Cholik F and Hanafi A. 2005. Review of Mud Crab Culture Research in Indonesia, Central Research Institute for Fisheries, PO Box 6650 Slipi, Jakarta, Indonesia, 310 CRA.

Hamidah, A., Fratiwi, M., dan J. Siburian. 2014. Kepadatan Kepiting Biola (Uca spp) Jantan dan Betina di Desa Tungkal 1 Tanjung Jabung Barat. Jurnal Penelitian Universitas Jambi Seri Sains 16 (2)

Hasan, Rusdi. 2014. Populasi dan Mikrohabitat Genus Uca di Kawasan Konversi Mengrove Pantai Panjang Bengkulu. jurnal 
seminar nasional XII pendidikan biologi. FKIP UNS 2015.

Karimah. 2017. Peran Ekosistem Hutan Mangrove Sebagai Habitat Untuk Organisme Laut". Jurnal biologi tropis. Vol 17 (2)

Karuniastuti, Nurhenuu. 2013. Peranan Hutan Mangrove Bagi Lingkungan Hidup. 6 (1):

Mardiyanto, Slamet Rahayu, Wiryanto dan Sunarto. 2018. Keanekaragaman Kepiting Biola Di Kawasan Mangrove Kabupaten Purworejo, Jawa Tengah". Jurnal Bioeksperimen. Vol 4 (1).

Murniati DC, Pratiwi R. 2015. Kepiting Uca di Hutan Mangrove Indonesia. Tinjauan Aspek Biologi Dan Ekologi untuk Eksplorasi. Jakarta: LIPI Press.

Odum, E.P. (1993). Fundamentals of Ecology. In T. Samingan ed. Yogyakarta (ID), Gadjah Mada: University Press.

Permata, Indah Sari., Prayogo Sari dan Burhanuddin. 2018. Keanekaragaman Jenis Kepiting Biola (Uca spp) di Hutan Mangrove "Mepawah Mangrove Park" Desa Pasir Kecamatan Mepawah Hilir Kabupaten Mepawah. Jurnal Hutan Lestari. Vol. 6 (4): 921-932.

Pratiwi, R. 2010. Asosiasi Krustacea Di Ekosistem Padang Lamun
Perairan Teluk Lampung. Ilmu Kelautan. 15(2):66-76.

Pratiwi, R. \& Astuti, O. (2012). Biodiversitas Krustasea (Decapoda, Brachyura, Macrura) dari Ekspedisi Perairan Kendari 2011 (Biodiversity of Crustacean (Decapoda, Brachyura, Macrura) from Kendari Waters Expedition 2011). ILMU KELAUTAN: Indonesian Journal of Marine Sciences 17(1) 8-14.

Putriningtias, A. et al., 2019. Keanekaragaman Jenis Kepiting di Ekosistem Hutan Mangrove Kula Langsa, Kota Langsa, Aceh. Jurnal Biologi Tropis, 19 (1):101107.

Rizal, M. et al., 2017. Struktur Komunitas Uca Spp. Dikawasan Hutan Mangrove, Bedul Utara, Taman Nasional Alas Purwo, Jawa Timur. Jurnal Parameter. Vol 29 (1).

Rosenberg, M. 2001. Filddler Crab Claw Shape Variation: a Geometric Morphometric Analysis Across the Genus Uca (Crustacea: Brachyura: Ocypodidae). Biological Jurnal of the Linean Society, 75 (13): 147-162.

Siburian, J., Suprayogi, D., dan A. Hamidah. 2014. Keanekaragaman Kepiting Biola (Uca spp) di Desa Tungkal 1 Tanjung Jabung Barat. Jurnal Biospesies 7 (1): 22-28. 